\title{
Increasing Ventilation Pressure Increases Cortical Subarachnoid Cerebrospinal Fluid Prostanoids in Newborn Pigs
}

\author{
ROBERT MIRRO, WIIIIAM ARMSIFAD, DAVII) BUSIIA, ROBIRI ( \\ (HARIES IHITIIER

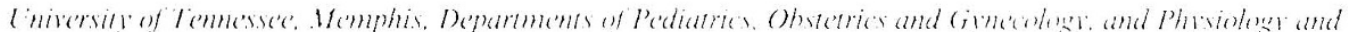 \\ Biophasics Memphis. Tennessee 3816.3
}

\begin{abstract}
ABSTRACI. This study examines the responses of pial arterioles and venules to increased mean airway pressure $\left(P_{\text {an }}\right)$ in newborn pigs. We further characterized the changes in cortical subarachnoid cerebrospinal fluid prostanoids with increased $P_{\text {aw }}^{-}$, both before and after cyclooxygenase inhibition with indomethacin. Eight chloralose anesthetized newborn pigs were equipped with closed cranial windows and ventilated with a conventional infant pressure-cycled respirator. Increasing $P_{\text {in }}$ from $3.2 \pm 0.3$ $\mathrm{cm}$ water to $14.3 \pm 0.6 \mathrm{~cm}$ water did not change pial arteriole or venule diameters. ('erebrospinal fluid prostanoids (6-keto-P( $\mathrm{FF}_{1, \alpha}, \mathrm{TxB}_{2}, \mathrm{P}\left(\mathrm{FF}_{2}\right.$, and $\mathrm{P}\left(\mathrm{FF}_{2 n}\right)$, however, were increased reversibly ( 3 - to 5 -fold) by increasing $P_{\text {:an. }}$. After indomethacin $(5 \mathrm{mg} / \mathrm{kg}$, intravenous) pial arterioles constricted approximately $15 \%$ with increased $P_{\text {an }}^{-}$. These results suggest that increasing ventilation pressure increases brain prostanoid production. Prostanoids appear to inhibit vasoconstriction and may be important in maintaining cerebral blood flow during the stress of mechanical ventilation. (Pediatr Res 22: 647-650, 1987)
\end{abstract}

\section{Abbreviations}

$P_{: \text {u }}^{-}$, mean airway pressure

CSF, cerebral spinal fluid

im, intramuscular

iv, intravenous

PIP, peak inspiratory pressure

PFEP, peak end expiratory pressure

$P(i$, prostaglandin

$\mathrm{T}_{\mathrm{X}} \mathrm{B}_{2}$, thromboxane $\mathrm{B}_{2}$

PVII/IVI, periventricular/intraventricular hemorrhage

Positive pressure ventilation commonly is used in neonatal intensive care units. We have noted previously that cerebral perfusion is maintained during positive pressure ventilation of newborn pigs despite signilicant reduction of cardiate output (1). In addition we have found that locally produced prostanoids are an important factor in the maintenance of cerebral blood llow during hemorrhagic hypotension (2) and in the increase in cerebral blood flow during asphyxia (3) in the neonatal pig. These

Received May 14, 1987: accepted July 29, 1987.

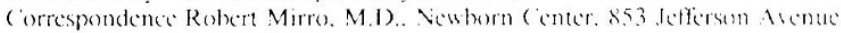
Room 201, Memphis IN 38163

Supported in part by research grants from the Vational Institules of Health, the American Ileart Association-lennessec Allibate and a program profect gram low

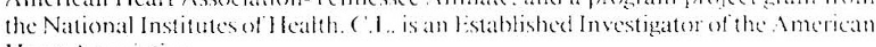
leart Association
Iwo observations led to the hypothesis that prostamoids also may play a role in the maintenance of cerebral perfusion during positive pressure rentilation. The objective of the present studs is to investigate the role of locally produced prostanoids in controlling microcerebral vascular tone during periods of increased airway pressure.

The use of the closed cranial window kechnigue allows direct visualization of pial arterioles and veins and provides the opportunity to sample cortical subarachnoid (SF: which can be used to measure cerebral prostanoid symthesis (4). In the present study we used the cranial window to observe the response to pial arterioles and venules $(50-20() \mu m)$ to positive pressure ventibtion. Further. we quantificd the effect of positive pressure ventilation in the levels of prostanoids in subarachnovid (SF samples taken from the cranial window.

\section{MFTHOISS}

I:ight piglets (0.6-1.6 kg. age $1-5$ days) were anesthetied with ketamine hydrochloride $(3.3 \mathrm{mg} / \mathrm{kg}$. im) and acepromarine $(3.3$ $\mathrm{mg} / \mathrm{hg} . \mathrm{im}$ ) and then maintained on a-chloralose (5) $\mathrm{mg} / \mathrm{hg}$ initially followed by $5 \mathrm{mg} / \mathrm{kg} / \mathrm{h}$. iv). (atheters were placed into a femoral vein and artery. The venous catheter allowed for drug administration while the arterial atheter was used for continueus blood pressure monitoring and for withdrawal of arterial blood gas and pH samples. Blond pressure was determined using a Statham pressure transducer and a (iould recorder. The trichea was cannulated with a $3 .($ ) $\mathrm{mm}$ (id) straight endotratheal tube and tied in place 10 prevent air leak. The animals were ventibated with an infant pressure respirator (Bourns BP 2(0). Bourns l ife Systems. Riverside. (A), and the proximal airwaly pressure was monitored continuously. The animals were ventilated with room air with initial ventilatory parameters of $2(0-30$ hreaths per minute. an inspiratory time of $0.5 \mathrm{~s}$. a PIP of $12 \ldots 15 \mathrm{~cm}$ watter. and a PEEP of 2 ro. Body temperature was maintaned at $37-$ $38^{\circ}$ ( with a water-circulating heating pad.

The scalp was removed. and a hole $2 \mathrm{~cm}$ in diameter was made in the skull over the parietal cortex. The dura and arachnoid membranes were cut without touching the brain. and all cut edges were reflected over the bone so that the subarachnoid space was not exposed to damaged tissue. A stainless sted and glass cranial window was placed in the hole and cemented into place with dental acrylic. Ihe space under the window was tilled with artificial CSF (22) me K(1. $1.32 \mathrm{mg} . \mathrm{Mg}(1,221 \mathrm{mg} \mathrm{(aCl}, 7710$

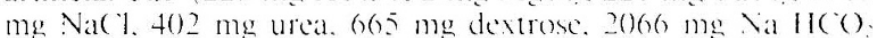

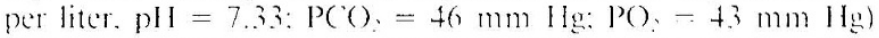
through needles incorporated into the sides of the window. The rolume of fluid directly under the window is approximate son ul and was continuous with the subarachnoid space. After implantation of the window. at least 30 min was allowed before experimentation was begun. 
Pial vessels were observed with a Wild M75 trinocular stereomicroscope, a television camera (model VC-65SL, Dage-MTI, Michigan City, IN) mounted on the microscope, and a video monitor (model CT 1930V, Panasonic Corp., Secaucus, NJ) Vessel diameter was measured with a video microscaler (Model VPA 1000 , For-A-Corp, Los Angeles, CA).

Protocol. The CSF under the cranial window was replaced, and pial arteriole and venule diameters were measured during an initial control period of five minutes. During this period the animals were ventilated at a low mean airway pressure $\left(\mathrm{P}_{\mathrm{aw}}^{-}=\right.$ $3.2 \pm 0.3 \mathrm{~cm}$ water). At the end of this 5 -min control period 300 $\mu \mathrm{l}$ of CSF from under the window was collected and frozen for prostanoid analysis and the CSF under the window replaced. Airway pressure then was increased by increasing both the PIP (to $18-20 \mathrm{~cm}$ water) and the PEEP (to $8-10 \mathrm{~cm}$ water) thus maintaining a constant tidal volume and $\mathrm{PCO}_{2}$. The $\mathrm{P}_{\mathrm{aw}}^{-}$at this time was $14.3 \pm 0.6 \mathrm{~cm}$ water. This pressure was selected from previous experience which has shown that this airway pressure would decrease cardiac output without altering arterial blood pressure (1). Furthermore, we know from this same previous study that sagittal sinus pressure would be increased at this $\mathrm{P}_{\mathrm{aw}}^{-}$ thus forcing the cerebral circulation to accommodate to an increase in venous pressure. During this 5 -min period the response of the pial vessels was recorded. At the end of five minutes a second sample of CSF was taken and the ventilation returned to the control settings ( $\mathrm{P}_{\mathrm{aw}}^{-}=3.2 \pm 0.3 \mathrm{~cm}$ water). During a third period (control 2) the vessels were measured again. At the end of this 5-min period a third CSF sample was taken. We then administered indomethacin trihydrate $(5 \mathrm{mg} / \mathrm{kg}$, iv). The dose of indomethacin used has been shown previously to cross the blood-brain barrier in sufficient quantity to inhibit the formation of cyclooxygenase metabolites (5) on the cerebral surface. During the ensuing 30- to 45-min period the CSF under the window was flushed several times. The protocol then was repeated at the same three airway pressures (control 1 :increased $\mathrm{P}_{\mathrm{aw}}^{-}$:control 2). No CSF samples were collected after indomethacin as previous experience (4) has shown that CSF prostanoids are undetectable after this dose of indomethacin.

Sagittal sinus pressure. Four piglets of similar size and age were prepared and ventilated as above except that a sagittal sinus catheter was placed instead of a cranial window. A midline scalp incision was made and a 23-gauge teflon catheter was inserted into the sagittal sinus. Sagittal sinus pressure as well as proximal airway pressure were then monitored in the same manner as arterial blood pressure. Airway pressure then was increased in a gradual stepwise fashion from a $\mathrm{P}_{\mathrm{aw}}$ of $3 \mathrm{~cm}$ water to a $\mathrm{P}_{\mathrm{aw}}^{-}$of 40 $\mathrm{cm}$ water.

Time control animals. Four additional animals were prepared as described above and pressure ventilated for $4 \mathrm{~h}$. At hourly intervals the airway pressure was increased. Pial arteriolar and venule measurements were recorded to insure that responses of the vessels were consistent.

Prostanoid analysis. CSF samples were analyzed for 6-keto$\mathrm{PGF}_{1 \kappa}$ (6-keto- $\mathrm{PGF}_{1 \kappa}$ ), $\mathrm{TxB}_{2}, \mathrm{PGE}_{2}$, and $\mathrm{PGF}_{2 \alpha}$ using radioimmunoassay methods previously described (4). Antibodies to 6-keto-PGF $\mathrm{P}_{1 \alpha}, \mathrm{TxB}_{2}, \mathrm{PGE}_{2}$, and $\mathrm{PGF}_{2 \alpha}$ were produced in rabbits immunized with prostanoids coupled to thyroglobulin using the mixed anhydride method. Cross-reactivity of all the prostanoids with other eicosanoids tested was less than $1 \%$. The assays were performed in gelatin-Tris buffer using the appropriate tritiated prostanoid. After $24 \mathrm{~h}$ of incubation at $4^{\circ} \mathrm{C}$, the free fraction was separated from that bound to antibody by adsorbing the unbound ligand on activated charcoal. Data were handled by computer with determination of second order regression of tracer bound to antibody against unlabeled prostanoid by method of least squares. All unknowns were assayed at three dilutions; the unknown dilution curves and the standard curve had to be parallel before the results were used. Values are reported in pg/ ml.

Statistical analyses. Pial arteriole and venule diameters, systemic arterial pressure, and prostanoid levels were analyzed using repeated measures analysis of variance. If the $F$ value was significant, the Student-Newman-Keuls test was performed. A level of $p<0.05$ was considered significant in all statistical tests. Values are reported as means \pm SEM of raw values.

\section{RESULTS}

Increasing ventilation pressure had no effect on pial arteriole or venule diameters prior to treatment with indomethacin (Table 1). Table 1 also lists the airway pressures, mean arterial blood pressures, $\mathrm{pH}$, and blood gases recorded during this study.

Figure 1 shows the prostanoid values from this study. The levels at control 1 represent basal prostanoid levels and demonstrate that cortical CSF prostanoids are present without stimulating their production. The hydrolysis product of prostacyclin (6-keto- $\left.\mathrm{PGF}_{1 \alpha}\right), \mathrm{PGE}_{2}, \mathrm{TxB}_{2}$, and $\mathrm{PGF}_{2 \alpha}$ all increased significantly when $\mathrm{P}_{\text {aw }}^{-}$was increased. When $\mathrm{P}_{\mathrm{aw}}^{-}$was reduced (control 2) prostanoid levels returned to near baseline.

After the administration of indomethacin pial arterioles constricted $15 \%$ when $\mathrm{P}_{\mathrm{aw}}^{-}$was increased while the venule diameters were unchanged (Table I). When the $\mathrm{P}_{\mathrm{aw}}^{-}$was returned to its original value, the vessels returned to their original diameter.

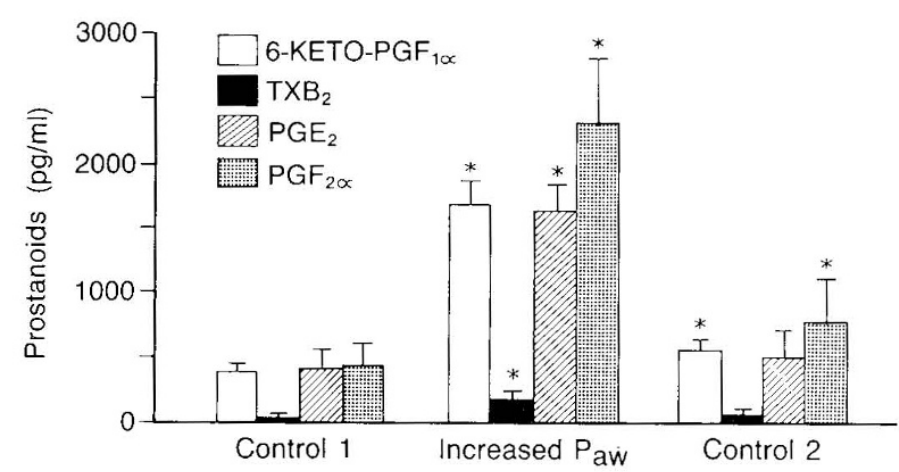

Fig. 1. Effects of increased $\mathrm{P}_{\mathrm{aw}}$ on cortical subarachnoid CSF prostanoids. Levels of 6-keto- $\mathrm{PGF}_{1 \kappa}, \mathrm{TXB}_{2}, \mathrm{PGE}_{2}$, and $\mathrm{PGF}_{2 \kappa}$ are given in $\mathrm{pg} /$ $\mathrm{ml}($ mean $\pm \mathrm{SEM})\left({ }^{*} p<0.05\right.$ compared to control 1$)$.

Table 1. Pial arteriole and venule diameters, Paw, mean arterial blood pressure (BP), and blood Gas $/ p H[m e a n \pm S E M(n=8)]$

\begin{tabular}{|c|c|c|c|c|c|c|}
\hline & \multicolumn{3}{|c|}{ Before indomethacin } & \multicolumn{3}{|c|}{ After indomethacin } \\
\hline & Control 1 & Increased $\mathrm{P}_{\overline{\mathrm{aw}}}$ & Control 2 & Control 1 & Increased $\mathrm{P}_{\overline{\mathrm{aw}}}$ & Control 2 \\
\hline Arteriole diameter $(\mu \mathrm{m})$ & $168 \pm 11$ & $174 \pm 14$ & $169 \pm 11$ & $174 \pm 14$ & $148 \pm 13^{*}$ & $175 \pm 14$ \\
\hline Venule diameter $(\mu \mathrm{m})$ & $192 \pm 12$ & $190 \pm 14$ & $188 \pm 13$ & $192 \pm 15$ & $187 \pm 9$ & $192 \pm 14$ \\
\hline $\mathrm{P}_{\overline{\mathrm{aw}}}\left(\mathrm{cm} \mathrm{H} \mathrm{H}_{2} \mathrm{O}\right)$ & $3.2 \pm 0.3$ & $14.3 \pm 0.6^{*}$ & $3.2 \pm 0.3$ & $3.1 \pm 0.3$ & $14.1 \pm 0.3^{*}$ & $3.1 \pm 0.3$ \\
\hline $\mathrm{BP}(\mathrm{mm} \mathrm{Hg})$ & $56 \pm 8$ & $56 \pm 9$ & $56 \pm 9$ & $53 \pm 6$ & $53 \pm 8$ & $52 \pm 6$ \\
\hline $\mathrm{pH}$ & $7.48 \pm 0.12$ & $7.46 \pm 0.18$ & $7.48 \pm 0.11$ & $7.46 \pm 0.14$ & $7.49 \pm 0.20$ & $7.47 \pm 0.18$ \\
\hline $\mathrm{PCO}_{2}(\mathrm{~mm} \mathrm{Hg})$ & $28 \pm 2$ & $27 \pm 3$ & $27 \pm 3$ & $28 \pm 3$ & $29 \pm 4$ & $27 \pm 4$ \\
\hline $\mathrm{PO}_{2}(\mathrm{~mm} \mathrm{Hg})$ & $82 \pm 4$ & $88 \pm 3$ & $86 \pm 3$ & $85 \pm 3$ & $89 \pm 2$ & $87 \pm 4$ \\
\hline
\end{tabular}

* Significantly different when compared to corresponding control 1 (Student-Newman-Keuls $p<0.05$ ). 


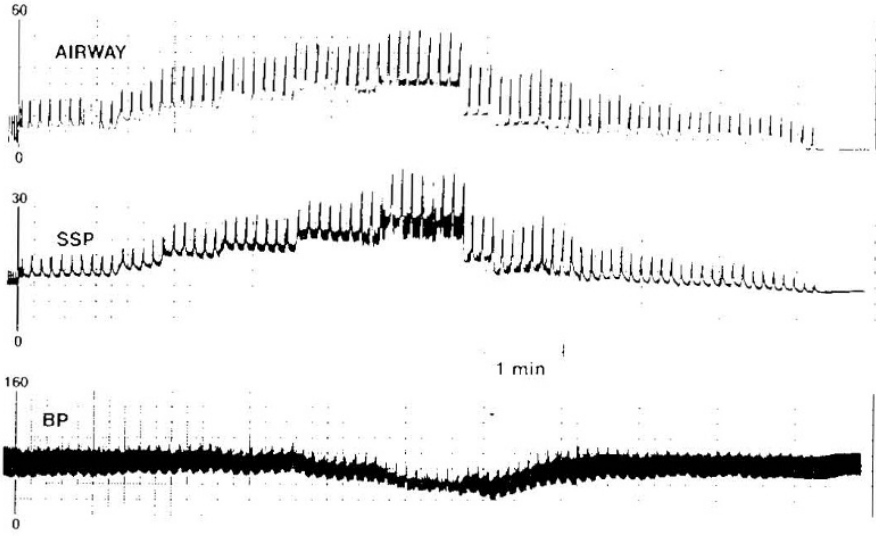

Fïg. 2. Recordings of proximal airway pressure $(A I R H I Y)$. sagittal sinus pressure (S.SP), and arterial blood pressure (BP) recorded white $P_{\text {aw }}^{-}$was increased from 10 to $38 \mathrm{~cm}$ water. Sagittal sinus pressure increases directly with airway pressure. Arterial blood pressure is affected beginning at a $\mathrm{P}_{\mathrm{aw}}^{-}$of approximately $35 \mathrm{~cm}$ water.

Blood pressure as well as arterial blood gases during these three periods were unchanged.

In all four animals prepared with sagittal sinus catheters increasing airway pressure was reflected directly in sagittal sinus pressure (Fig. 2). Baseline mean sagittal sinus pressure was $3 \pm$ 1.0 $\mathrm{mm} \mathrm{Hg}$ with minimal ventilation pressure $\left(P_{-\mathrm{m}}^{-}=3 \pm 0.2 \mathrm{~cm}\right.$ water) and increased to mean of $21 \pm 1.5 \mathrm{~mm} \mathrm{Hg}$ when $P_{\text {:aw }}^{-}$was $40 \mathrm{~cm}$ water. Arterial blood pressure was not affected until the $P_{\text {atw }}^{-}$was $36 \pm 2 \mathrm{~cm}$ water.

The lime control animals maintained vessel diameters constant when $P_{a x}^{-}$was increased. For example. pial arterioles were $165 \pm 8,167 \pm 3$. and $168 \pm 4 \mu \mathrm{m}$ for control 1 . increased $P_{\text {:aw }}$. and control 2 during the first increase in $P_{\text {aw }}$. On subsequent increases in $P_{\text {aw }}^{--}$arteriolar diameters were $167 \pm 6.168 \pm 8$. and 170) $\pm 8 \mu \mathrm{m}$ for control 1. increased $P_{i, 4}^{-}$, and control 2. Vo indomethacin was used in the time control animals.

\section{IDISCUSSION}

The results of the present study indicate that when ventilation pressure is increased, cortical subarachnoid (SF prostanoids increase to attenuate vasoconstriction.

Prostanoids play an important role in perinatal cerebrovascular physiology (6). Specifically, evidenee from our own laboratory suggests that prostanoids are involved in regulating perinatal cerebral blood flow during periods of asphyxia and hypotension. In newborn pigs inhibition of cyclooxygenase blocks the cerebral hyperemiat associated with asphyxia (3). When a similar animal preparation is subjected to hemorrhagic hypotension. (SF prostanoids increase except when the animals are treated with indomethacin. Indomethacin inhibits prostanoid production and brain blood flow falls (2).

Increasing ventilation pressure in newborn pigs decreases cardiac output and increases sagittal sinus pressure prior to decreasing systemic arterial pressure (1). Despite these cardiovascular effects, cerebral blood flow is maintained. The results of the present study suggest that the prostanoid system contributes to the maintenance of cerebral perfusion when the cardiovascular system is stressed by pressure ventilation. as with asphyxiated and hypotensive newborn pigs. likevation of airway pressure causes cortical subarachnoid ( $\mathrm{Sl}$ : prostanoids to increase. When prostanoid synthesis is inhibited. pial arterioles constrict in response to clevated P-- Thus, prostanoids appear to inhibit vasoconstriction during pressure ventilation.

The stress of mechanical pressure ventilation causes vasoconstriction in most vascular beds. Increased eerebral prostanoid synthesis during increased airway pressure appears to attenuate cerebral vasoconstriction thereby aiding in maintenance of ecrebral blood flow. As both vasodilator and vasoconstrictor prostanoids increase. We assume from the arteriolar response after indomethacin that dilator prostanoids (6)-keto-P(jF $F_{1 .}$ and $P\left(\mathrm{Fl}_{3}\right)$ play a dominant role. Furthermore, it is possible that the constrictor prostanoids are produced secondarily to a general prostanoid synthesis stimulation. Such a pressor response followed by cerebral prostanoid production could occur via cerebral adrenergic nervous stimulation or via circulating catecholamines. We have found that both o-adrenergic stimulation and topical norepinephrine constrict piglet cercbral arterioles (7). while topical norepinephrine causes dilator prostanoids to be relcased into the cortical subarachnoid (SF (8).

We cannot explain why the diameter of pial venules did not increase when intrathoracie pressure was increased. It mas he that the increased venous pressure does not reach distally to pial venules and that venous engorgement occurs only in the larger vessels of the brain.

A clear association exists between pressure ventilation and neonatal PVH/IVH (9) with more severe respirators illness haling a higher incidence of PVH/IVH. The role that increased intrathoracic pressure and thus increasing venous pressure plat in PVH/IVH has been discussed (9), and it appears that restricted venous return may contribute to PVH/IVH. Furthermore, involvement of prostanoids in the development of PVH/IVH has been suggested. Some authors (10) report inhibiting prostanoid synthesis with indomethacin prevents PVH/IVH. while others (11) have failed ito show such an advantage. Although none of these studies examined cerebral blood flow during indomethacin therapy. other investigators have shown in both newborn animals (3) and humans (12) that indomethacin decreases cerebral blood flow. Although a link between mechanical wentilation and PVH/ IVH appears possible. no previous work has demonstrated an association between mechanical ventilation and cerebral prostanoid production.

The closed cranial window technicue used in this study allows both direct observation of pial vessels and sampling of the cortical subarachnoid CSF that bathes the observed blood vessels. Prostanoids in cortical subarachnoid fluid appear to have originated from the cortical surfaces because C $\mathrm{SF}$ from the cisterna magna has much lower prostanoid concentrations under control conditions (4). Possible sourees of these prostanoids include cortical vessels autonomic nerves associated with these ressels. and/or brain parenchyma. We speculate from the evidence available from other tissues that 6-keto-P( $\mathrm{BF}_{1}$, and $\mathrm{TxB}$, are from the vessels while $P(j E$, is from the nervous tissue $(1.3-15)$. In the present experiment several possibilities exist for this local prostanoid production. In particular. it seems possible that when airway pressure is increased thus increasing venous pressure. the source of the measured prostanoids is the venous sistem. The major increase in venous pressure is probahly transmitted to the sagittal sinus. and it is possible that this is the main site of prostanoid sinthesis.

In summary, we have shown that increasing airway pressure using a conventional pressure-limited infant ventilator increases cerebral cortical production of prostanoids while not affecting pial arteriole or venule diameter. When prostanoid production is inhibited with indomethacin. pial arterioles constrict when Pa is increased. This evidence further supports the impact that mechanical ventilation can have on the peripheral vascular sistem and also supports the important role that prostanoids pla! in the regulation of the cerebral circulation of stressed neonates.

\section{RIIIIRIVC I:S}

1. Mirro R. Busija D). (ircen R. Leffler ( 1987 The relationship hetween mean sirwas pressure, cardiac output and orean blood flow with normal and decrased respirators compliance J Pediatr $1111: 101-106$

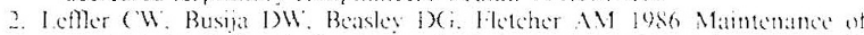
cerebral circulation during hemorthage hypotension in newhorn pigs: role of prostanoids. Circ Res $59,50,256$ ?

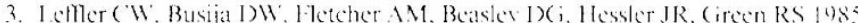


Effects of indomethacin upon cerebral hemodynamics of newborn pigs. Pediatr Res 19:1160-1164

4. Leffler CW, Busija DW 1985 Prostanoids in cortical subarachnoid cerebrospinal fluid and pial arterial diameter in newborn pigs. Circ Res 57:689-694

5. Leffler CW, Busija DW 1985 Arachidonic metabolism on the cerebral surface of newborn pigs. Prostaglandins 30:811-818

6. Leffler CW, Busija DW 1987 Arachidonic acid metabolites and perinatal cerebral hemodynamics. Sem Perinatol 11:31-42

7. Busija DW, Leffler CW, Wagerle C 1985 Responses of newborn pig pial arteries to sympathetic nervous stimulation and cxogenous norepinephrine. Pediat Res 19:1210-1214

8. Busija DW, Leffler CW 1987 Eicosanoid synthesis elicited by norepinephrine in piglet parietal cortex. Brain Res 403:243-248

9. Volpe JJ 1987 Neurology of the Newborn, 2nd ed. WB Saunders, Philadelphia

10. Ment LR, Duncan CC, Ehrenkranz RA, Kleinman CS, Pitt BR, Taylor KJW, Scott DT, Stewart WB, Gettner P 1985 Randomized indomethacin trial for prevention of intraventricular hemorrhage in very low birth weight infants. J Pediatr 107:937-943

11. Mahoney L, Caldwell RL, Girod DA, Hurwitz RA, Jansen RD, Lemons JA, Schreiner RL 1985 Indomethacin therapy on the first day of life in infants with very low birth weight. J Pediatr 106:801-805

12. Cowan F 1986 Indomethacin patent ductus arteriosus and cerebral blood flow. J Pediatr 109:341-344

13. Abdel-Halim MS, VanHolst H, Meyerson B, Sachs C, AnggArd E 1980 Prostaglandin profiles in tissue and blood vessels from human brain. $\mathrm{J}$ Neurochem 34:1331-1333

14. Gochlert UG, Ng Ying Kin NMK, Wolfe LS 1981 Biosynthesis of prostacyclin in rat cerebral microvessels and the choroid plexus. J Neurochem 36P:11921201

15. Hagen AA, White RP, Robertson JT 1979 Synthesis of prostaglandins and $\mathrm{TxB}_{2}$ by cerebral arteries. Stroke 10:306-309 